\title{
Article
}

\section{Epistemic beliefs and prior knowledge as predictors of the construction of different types of arguments on socioscientific issues}

Baytelman, Andreani and Iordanou, Kalypso

Available at http://clok.uclan.ac.uk/32042/

Baytelman, Andreani and Iordanou, Kalypso ORCID: 0000-0001-5930-9393 (2020) Epistemic beliefs and prior knowledge as predictors of the construction of different types of arguments on socioscientific issues. Journal of Research in Science Teaching, 57 (8). pp. 1199-1227. ISSN 0022-4308

It is advisable to refer to the publisher's version if you intend to cite from the work. http://dx.doi.org/10.1002/tea.21627

For more information about UCLan's research in this area go to http://www.uclan.ac.uk/researchgroups/ and search for <name of research Group>.

For information about Research generally at UCLan please go to http://www.uclan.ac.uk/research/

All outputs in CLoK are protected by Intellectual Property Rights law, including Copyright law. Copyright, IPR and Moral Rights for the works on this site are retained by the individual authors and/or other copyright owners. Terms and conditions for use of this material are defined in the policies page. 


\title{
Epistemic Beliefs and Prior Knowledge as Predictors of the \\ Construction of Different Types of Arguments on Socio-Scientific Issues
}

Andreani Baytelman, Kalypso Iordanou and Costas. P. Constantinou

\begin{abstract}
This study investigates whether university students' epistemic beliefs and prior knowledge about controversial socio-scientific issues (SSIs) can predict the different types of arguments that students construct. Two hundred forty-three university students were asked to construct different types of supportive arguments - social, ethical, economic, scientific, ecological - as well as counterarguments and rebuttals after they had read a scenario on a SSI. Participants' epistemic beliefs and prior knowledge were assessed separately. Results showed that students' epistemic beliefs and prior knowledge predicted the quantity, quality and diversity of the different types of arguments the students construct. In particular, students who held sophisticated epistemic beliefs about the structure of knowledge and exhibited relatively more robust prior knowledge scores produced arguments of greater quantity, better quality and higher diversity of argument types than students with less sophisticated epistemic beliefs and low prior knowledge scores. Educational implications are discussed.
\end{abstract}

Keywords: epistemic beliefs, prior knowledge, argument construction, socio-scientific issues, university education students. 


\section{Introduction}

The construction of arguments is an essential feature of scientific reasoning and an integral component of scientific literacy (Duschl, 2008; Erduran \& Jimenez-Aleixandre, 2007; Kuhn, Iordanou, Pease, \& Wirkala, 2008; NGSS Lead States, 2013; Yacoubian, 2018). Skilled argumentation entails not only the presentation of one's own position, but also consideration and evaluation of alternatives (Mason \& Scirica, 2006). Argumentation plays therefore a prominent role in efforts to grapple with controversial socio-scientific issues (SSIs), defined as open-ended, debatable, complex or ill-structured problems that require the consideration of social, ethical, economic, scientific, ecological perspectives (Dawson \& Venville, 2013; Sadler, 2009; Sadler \& Zeidler, 2005). Prior research has demonstrated that individuals' argument skills do not develop spontaneously. Yet the factors that facilitate the development of argument skills remains underdetermined, including when people engage in SSI (Asterhan \& Schwarz, 2016; Henderson, McNeill, González-Howard, Close, \& Evans, 2018; Iordanou \& Constantinou, 2014; 2015; Zeidler, Herman, \& Sadler, 2019). To gain a fuller understanding of how argument skills develop, it has been suggested that we could pay closer attention to learners' epistemic thinking and its possible interaction with students' argument skills (Barzilai \& Chinn, 2018; Iordanou, 2016a; Kuhn, Zillmer, Crowell \& Zavala, 2013).

Our aim in this study is to investigate whether individuals' epistemic beliefs and prior knowledge about controversial socio-scientific issues (SSIs) can predict students' argument skills. We are also interested in examining the effect of context on argument skills. The question of whether and to what extent argument skills are context specific is still an open one, given that there are mixed findings regarding the transferability of argument skill from one context to another (Iordanou, 2010; Osborne et al., 2016; Udell, 2007). In particular, the study investigates whether prior knowledge, epistemic beliefs and SSI-context predict the quantity, quality and diversity of different types of arguments constructed by university students on a complex, 
controversial, socio-scientific topic. By doing this, we hope to contribute to the development of a theoretical framework that will describe the relationship between epistemic beliefs, prior knowledge and construction of arguments on SSIs.

\section{Conceptualization of Epistemic Beliefs}

Epistemic beliefs refer to individuals' beliefs about the nature of knowledge and the process through which knowledge develops (Hofer \& Pintrich, 1997; Muis, Pekrun, Sinatra et al., 2015; Sandoval, Greene, \& Bråten, 2016). According to Kitchener (2002), "epistemology” is a theory of knowledge and how it develops, while "personal epistemology" is a personal theory about developing knowledge.

Different models have been proposed on how to conceptualize and examine epistemic beliefs. Perry (1970) proposed a developmental model that described nine levels in epistemic beliefs, ranging from the belief that knowledge is objective, to the belief that knowledge is radically subjective, and finally to the belief that knowledge has objective and subjective aspects. Based on Perry's scheme, Kuhn and colleagues (e.g. Kuhn, 1991; Kuhn et al., 2000) developed a framework for the development of epistemic beliefs, which progresses along three general epistemic levels: absolutist, multiplist, and evaluativist. Absolutists view knowledge as comprising certain and absolute facts and expertise as the basis for knowing. Absolutists express high certainty about their own beliefs. Multiplists are skeptical about expertise, emphasizing that experts disagree with each other and are inconsistent over time. Evaluativists deny the possibility of certain knowledge, and acknowledge that viewpoints can be compared and evaluated to assess relative merits. These positions are considered developmental, rather than variants of cognitive style (Iordanou, 2016a; Kuhn et al., 2000).

Another model, the multidimensional approach, proposed that epistemic beliefs should be described as a system of more or less independent beliefs (epistemic dimensions), conceptualized as beliefs about the certainty (related with the stability of knowledge), simplicity (related with the structure of knowledge), and source of knowledge, as well as beliefs about the 
speed and ability of knowledge acquisition (Schommer, 1990; Schommer, Crouse, \& Rhodes 1992; Schommer-Aikins, 2004). While the dimensions of certainty, simplicity and source in Schommer's conceptualization fall under the more generally accepted definition of epistemic beliefs - known as beliefs about the nature of knowledge (certainty, simplicity) and knowing (source) (Hofer \& Pintrich, 1997) - the speed and ability dimensions are controversial because they mainly concern beliefs about learning (speed) and intelligence (ability). Hofer and Pintrich (1997) argued that epistemic beliefs should be defined more purely, with two dimensions concerning the nature of knowledge (what one believes knowledge is) and two dimensions concerning the nature or process of knowing (how one comes to know). According to Hofer and Pintrich (1997), the two dimensions concerning the nature of knowledge are: (a) Simplicity of Knowledge, ranging from the belief that knowledge consists of an accumulation of more or less isolated facts to the belief that knowledge consists of highly interrelated concepts; and (b) Certainty of Knowledge, ranging from the belief that knowledge is absolute and unchanging, to the belief that knowledge is tentative and evolving. The two dimensions concerning the nature of knowing are: (c) Source of Knowledge, ranging from the conception that knowledge originates outside the self and resides in external authority from which it may be transmitted, to the conception that knowledge is actively constructed by the person in interaction with others; and, (d) Justification for Knowing, ranging from justification of knowledge claims through observation and authority or on the basis of what feels right, to the use of rules of inquiry and the evaluation and integration of different sources (Hofer \& Pintrich, 1997). Accordingly, Hofer and Pintrich's model differs from Schommer's in that it omits the nature of learning factors and adds another nature of knowing factor, namely justification. Additionally, Conley and colleagues (2004) suggested a new factor under the nature of knowledge factors, the Development of Knowledge.

Despite the differences between the developmental and the multidimensional models, Pintrich (2002) acknowledged that, although the endpoint of development of epistemic beliefs 
varies from model to model, "the fairly well-established trend is that individuals move from some more objectivist perspective through a relativistic one, to a more balanced and reasoned perspective on the objectivist-relativistic continuum, with this latter position reflecting a more sophisticated manner of thinking" (Pintrich, 2002, p. 400).

\section{Epistemic Beliefs and Argument Skills}

According to Kuhn's (2001) theoretical model, epistemic beliefs support argument skills. In particular, epistemic beliefs inform intellectual values that deal with questions such as "Is there a point to arguing?" and intellectual values, in turn, affect the disposition to apply argumentation strategies. Yet, according to Mason and Scirica (2006), argument skills may indeed be enhanced or constrained by epistemic beliefs, that is, by more or less advanced representations about the nature, source, justification, validation, and appropriation of knowledge.

The relationship between epistemic beliefs and argument skills has been the focus of several studies over the past thirty years (Barzilai \& Eshet-Alkalai, 2015; Bell \& Linn, 2000; Berland et al., 2016; Duschl, 2008; Henderson et al., 2018; Iordanou, 2016b; Mason \& Scirica, 2006; Nussbaum, Sinatra \& Poliquin, 2008; Wu \& Tsai, 2011; Xiao \& Sandoval, 2016). These studies report remarkably consistent findings, despite variation with respect to the epistemic beliefs framework the studies employ and the instruments they use to assess epistemic beliefs. In particular, a relationship has been found between advanced epistemic beliefs, evaluativist beliefs, and individuals' ability to generate alternative arguments and counterarguments (Iordanou, 2016b; Iordanou \& Constantinou, 2015; Kuhn, 1991; Mason \& Scirica, 2006; Zavala \& Kuhn, 2017). In addition, a relationship has been reported between evaluativist epistemic beliefs and comprehension and evaluation of arguments, during reading (Barzilai \& Eshet-Alkalai, 2015; Iordanou, Muis, \& Kendeou, 2019).

Even though previous empirical studies have revealed that there is a relationship between individuals' epistemic beliefs and the number and/or the quality of socio-scientific arguments, 
counterarguments, and rebuttals that they produced, the possible contribution of epistemic beliefs to the diversity of different types of arguments that individuals produce has not yet been investigated. In the present study we address this gap in the literature, namely whether epistemic beliefs and prior knowledge predict construction of different types of arguments.

Furthermore, previous research suggests that epistemic beliefs may limit or promote conceptual change and topic conceptual understanding (Amin, Smith \& Wiser, 2014; Stathopoulou \& Vosniadou, 2007a; 2007b; Trevors, Kendeou, Bråten, \& Braasch, 2017a), which means that the investigation of the interrelationship of epistemic beliefs, topic conceptual understanding and argumentations skills is an important research issue.

\section{Prior Knowledge and Argument Skills}

According to Toulmin (1972), argumentation is intertwined with reasoning and critical thinking and is the mechanism for creating and using knowledge (Willard, 1989). Researchers also highlight that domain-specific knowledge has a critical role in scientific reasoning, and that wellstructured knowledge can sustain higher levels of reasoning than poorly structured knowledge (Amin, Smith \& Wiser, 2014; Carey, 1985; Chinn \& Duncan, 2018; Koslowski, 1996; Osborne et al., 2016; Osborne, \& Simon, 2008; Schauble, 1996; Stathopoulou \& Vosniadou, 2007a; 2007b; Trevors, Kendeou, Bråten, \& Braasch, 2017; Von Aufschnaiter et al., 2008). Yet, our understanding of how prior-knowledge contributes to argumentation skills is still not clear (Grooms, Sampson, \& Enderle, 2018). For example, some researchers support that sufficient prior knowledge is a prerequisite for engagement in argumentation (Sadler \& Fowler, 2006; Sadler \& Zeidler, 2005; Von Aufschnaiter et al., 2008), while others support that prior knowledge alone does not determine the quality of argument skills, supporting that topic knowledge is probably a necessary, but not a sufficient condition for skilled scientific argumentation (Iordanou \& Constantinou, 2015; Kuhn, 1991; Means and Voss, 1996).

Furthermore, previous research that examined the relation between prior knowledge and argument skills, has focused on how prior knowledge affects the quantity and quality of 
arguments. Yet, the possible relation between prior knowledge and the diversity of different types of arguments produced has not been examined. The present work addresses this gap in the literature by examining the possible relation between prior knowledge and all the different measures of argument skills, namely quantity, quality and diversity of arguments produced.

\section{The Present Study}

In the present study, we extend the literature by investigating whether university students' epistemic beliefs and prior knowledge about controversial socio-scientific issues (SSIs) predict the quantity, the quality and the diversity of the different types of arguments that students construct. We investigate different types of arguments such as social, ethical, economic, scientific and ecological because the three SSIs chosen for this study - Vaccination or not against the NUEVO flu virus, Consumption of bottled vs. tap water, Usage of underground vs. overhead high voltage lines in residential areas - involve phenomena which have societal, ethical, economic, scientific and ecological aspects. A similar classification was used by $\mathrm{Wu}$ and Tsai (2011), who also investigated the relationship among students' epistemic beliefs and their informal reasoning on nuclear power usage.

In particular, we set out to answer two research questions:

(1) What is the relationship between university students' prior knowledge and epistemic beliefs and the number, quality and diversity of arguments they construct on a controversial socio-scientific topic?

(2) What is the relationship between the socio-scientific topic context experienced by students and the number, quality and diversity of the arguments that they construct about a controversial socio-scientific topic?

We focus on the construction of different types of arguments because the ability to produce arguments that integrate multiple positions or accounts reflects one's depth of reasoning 
(Nussbaum \& Schraw, 2007). Also, the ability to consider a variety of perspectives is fundamental for decision-making, especially in the case of SSIs, which are complex, open-ended problems which involve controversial and conflicting information (Herman, Zeidler, \& Newton, 2018; . Lee, Lee, \& Zeidler, 2019; Lindahl, Folkesson, \& Zeidler, 2019; Zeidler, 2014). Although previous research has shown that there is a relationship between sophisticated epistemic beliefs and argumentation skills, in terms of the number of arguments produced about an issue (Mason \& Scirica, 2006; Songer \& Linn, 1992; Wu \& Tsai, 2011) and the quality of arguments produced (Baytelman, Iordanou \& Constantinou, 2016; ; Barzilai \& Eshet-Alkalai, 2015; Berland et al., 2016; Jiménez-Aleixandre, 2014; McNeill et al., 2017; Ryu \& Sandoval, 2012), particularly the ability to construct counterarguments (Iordanou, 2016b; Wu \& Tsai, 2011; Zavala \& Kuhn, 2017), the relationship between epistemic beliefs and the types of arguments produced (diversity of arguments) has not been investigated yet. In order to develop a context which enables the construction of multiple types of arguments, we used SSI scenarios. Being complex, open-ended, contentious, cross-curricular dilemmas, with social, ethical, economic, scientific, ecological aspects, with no definitive answers, SSI scenarios are ideal candidates for the construction of different types of arguments (Lindahl, Folkesson \& Zeidler, 2019; Sadler \& Zeidler, 2005; Zeidler, Herman, Ruzek, Linder. \& Lin, 2013).

We hypothesize that students holding evaluative epistemic beliefs have the ability not only to evaluate different given arguments but also to produce different types of arguments, reflecting their ability to think about a complex issue from multiple perspectives. We also hypothesize that students with more robust prior knowledge will produce more arguments (Means \& Voss, 1996), arguments of better quality (Iordanou \& Constantinou, 2015; Grooms, Sampson, \& Enderle, 2018; Osborne et al., 2016) and diversity. In particular, we hypothesize that prior knowledge will be related to the ability of constructing different types of arguments, given the relationship that has been reported between argument skills and prior knowledge (Zohar 
\& Nemet, 2002), particularly between producing counterarguments and prior knowledge (Voss, Blais, Means, Greene \& Ahwesh, 1986).

To answer our research questions, we asked university students to construct social, ethical, economic, scientific and ecological arguments about SSIs and to complete instruments that assess their epistemic beliefs and prior knowledge on SSIs. We used three different SSIscenarios to investigate further whether the topic context has an effect on students' ability to construct different types of arguments, examining whether the ability to construct different types of arguments is context specific.

\section{Method}

\section{Participants}

Participants were 243 undergraduate students in Education at a public University in South Europe. $93 \%$ were females and $7 \%$ were males, with an overall mean age of $21(S D=1.5)$. The collection of data in an almost female only sample was not a choice but a limitation of this study, a constraint imposed by the student population of this University. Students were between the second and fourth year of their study. All participants were elementary or early childhood education majors and were enrolled in a required science education course. Participation in the research was optional. The students were recruited through advertisements and were compensated for their participation with a small bonus mark of $3 \%$ on the science education course. All students who expressed interest to participate in this study were accepted. The participants were Caucasian native speakers of Greek and shared a homogeneous middle-class social background and Greek language. There were no bilingual learners. With very few exceptions, all participants had completed their secondary education in public schools. However, 
they were from a diverse school subject background; some of them were specialized in Physics, others in Mathematics and others in Greek literature or Economics. Entrance to this university is competitive and it is based on participants' performance in a national matriculation examination. All materials and assessment tools which were used for this study were in Greek language.

\section{Materials and Coding}

\section{Socio-scientific issue scenarios.}

Three different SSI-dilemmas were developed and used in the present study. The first SSI-dilemma was on Usage or not usage of vaccines against the NUEVO flu virus. The second SSI-dilemma was on Consumption of bottled vs. tap water. The third SSI-dilemma was on Usage of underground vs. overhead high voltage lines in residential areas. Our rationale for the choice of these SSI-dilemmas is the following: (a) During the last decade, SSIs such as safety and usage of vaccines, high voltage lines and consumption of bottled vs. tap water have attracted increasing attention in XXX, therefore students might have been more motivated to engage in thinking about these topics; (b) the participants of this study had already learned about vaccines, drinking water and high voltage lines in their science classes at secondary school and they had basic prior knowledge regarding these issues; and (c) the three different SSI-scenarios all have different scientific, social, economic, ecological and ethical aspects.

Each SSI-scenario was presented on one A4 sheet of paper. The first text comprised 194 words, the second 152 words and the third 169 words (in original version, in XXXX language). All three texts were developed by the authors and contained conflicting information, presenting different views on the dilemma presented in each scenario. Each of the three scenarios/texts was organized into four parts: the first part was a neutral introduction to the SSI-dilemma; the second part introduced one position of the dilemma; the third part presented the opposing position of the dilemma, the fourth part asked the students to make an informed decision regarding each SSI. 
Both positions were supported by extra evidence (on a separate sheet) and were introduced in a balanced manner in relation to the aspects examined. A variety of sources were used for the additional evidence, such as official websites of relevant government agencies, articles in scientific and professional journals and magazines, online conference presentations, professional blogs, websites of advocacy groups, laypeople's and non-experts' opinions, newspaper articles, and teaching resources. The sequence of information on different positions as presented on the leaflets was reviewed by three expert researchers to make sure that it was balanced with respect to the two positions and would not bias the results of the study.

We included three different SSI-scenarios to limit the possible context dependence and increase the generalizability of our results. Each text and corresponding evidence were printed on separate sheets of paper (see Appendices A and B) and were presented to the participants to be used in their efforts to construct arguments. Because of time constraints, participants were randomly assigned to three equal groups $(N=81)$ to complete one of the three SSIs, rather than all three of them. We investigated the effect of context on the construction of different types of arguments using dummy variables after controlling for topic prior knowledge and epistemic beliefs.

\section{Epistemic beliefs measures.}

To assess participants' epistemic beliefs, we used the Dimensions of Epistemological Beliefs toward Science Instrument (DEBS) (Baytelman \& Constantinou, 2016). The DEBS instrument focuses on the nature and characteristics of epistemic beliefs (epistemic dimensions) and is the only multidimensional instrument that has been validated in the particular culture that the research was conducted. The 30-item DEBS Instrument captures three dimensions concerning knowledge - certainty of knowledge, simplicity of knowledge and development of knowledge and two dimensions concerning knowing - source of knowledge and justification of knowledge. Each dimension consisted of six items and the items were rated on a four-point Likert-scale, ranging from strongly disagree (1) to strongly agree (4). High scores on this measure represent 
more sophisticated beliefs, while low scores represent less sophisticated beliefs. In the present research, the face and content validity of the DEBS Instrument was established by the input of two experts in Epistemic Cognition and two experts in Science Education (Baytelman \& Constantinou, 2016). The internal consistency of each subscale of the instrument was examined using the Cronbach alpha coefficient. The construct validity of the instrument was examined with Confirmatory Factor Analysis (CFA) using SPSS Amos 20.0, which indicates the underlying hypothesized factor structure based on the theoretical framework (see Appendix C). Table 1 displays examples of items of each subscale of the DEBS Instrument, the item-rest correlation for each example item, and the Cronbach alpha coefficient of each subscale.

Table 1

The confirmatory factor analyses confirmed our hypothesized dimensions, with the fit indices showing a reasonably good fit between the five-dimensional model and the data. Particularly, in our analyses, we used five fit indices with different measurement properties, following recommendations in the literature (Griffin, 2005; Hu \& Bentler, 1999). Specifically, the fit indices with recommended values that we used in our study are: the chi squared difference test $\left(\mathrm{x}^{2} / \mathrm{df}\right)<2$., Goodness-of-Fit Index $(\mathrm{GFI})$, Comparative Fit Index $(\mathrm{CFI})$ and Incremental Fit Index $(\mathrm{IFI})>0.90$, and Root Mean Square Error of Approximation $($ RMSEA $) \leq .08$.

The chi-squared difference test indicates the difference between observed and expected covariance matrices. GFI is a measure of fit between the hypothesized model and the observed covariance matrix. CFI and IFI analyze the model fit by examining the discrepancy between the data and the hypothesized model. RMSEA avoids issues of sample size by analyzing the discrepancy between the hypothesized model, with optimally chosen parameter estimates, and the population covariance matrix. According to $\mathrm{Hu}$ and Bentler (1999), a chi squared difference 
test $\chi 2 /$ df value less than 3.0 (Watkins, 1989), Goodness-of- Fit Index (GFI), Comparative Fit Index (CFI), Incremental fit index (IFI) values greater than 0.90 (Brown, 2006) and a Root Mean Square Error of Approximation (RMSEA) value less than .06 indicate a model with a good fit. CFI values close to or greater than 0.95 indicate an excellent fit (Hu \& Bentler, 1999). Values of RMSEA $\leq 0.08$ are often considered as indicating acceptable fit (Hu \& Bentler, 1999).

Table 2 displays the fit indices used and the corresponding values from our analyses.

Table 2

\section{Prior knowledge measures.}

In the present study, prior knowledge is defined as domain-specific content knowledge, including knowledge of concepts, principles, facts and theories of a subject, but also an understanding of how those concepts and principles are organized (Kleickmann et al., 2012; Shulman, 1986). One method for assessing a single concept or principle is the use of concept questions (Mazur, 1997). For assessing the organization and structure of an individual's knowledge within a particular domain and the efficiency with which the knowledge can be used, Williams (1998) suggested using concept maps. Concept maps are a direct method of looking at the organization and structure of an individual's knowledge within a particular domain and at the fluency and efficiency with which the knowledge can be used (Novak, 1998; 2006; 2010; Novak \& Cañas, 2008).

To assess their prior knowledge, students were asked to answer five open-ended questions and to construct a concept map for each SSI. We evaluated prior knowledge in two different levels: 1) shallow (surface) conceptual understanding, which was assessed by open-ended questions that examined distinct basic scientific concepts related to each SSI; and, 2) deep conceptual understanding, which was assessed by a concept map requiring appropriate 
relationships between the relevant concepts. Designing concept maps has been described as an appropriate approach to identify students' mental representations because it reveals students' understanding of how concepts and principles of a subject are organized and interrelated (Novak, 1998; 2006; 2010; Novak \& Cañas, 2008; Yin, Vanides, Ruiz-Primo, Ayala, \& Shavelson, 2005). A concept map can provide evidence for the important distinction between deep and surface learning (Hay, 2007; Novak, 1998). The structure of a concept map is defined by the number of nodes and the relations between the nodes (e.g., organizational as in hierarchical concept maps vs. relational as in network concept maps). The more valid connections appearing among facts, ideas, and procedures, the better the understanding is (Hiebert \& Carpenter, 1992; Hiebert \& Lefevre, 1986). Concept maps can be used for distinguishing between deep and surface understanding, because concept maps help students reveal how they organize the concepts in their minds and the connections they make across topics (Hay, 2007). Additionally they can be used for distinguishing between meaningful and rote learning "because [concepts that are learnt by rote] are stored arbitrarily and non-substantively in cognitive structure, [therefore they] cannot be recalled and confer interference with new, related learning and recall of related information" (Novak, 1998).

For the development of the prior knowledge questionnaires, four steps were followed: (a) Review of relevant literature for the development of a preliminary item pool; (b) Interviews with two experts in Science Education for the validation and optimization of items; (c) Pilot studies for determining the internal consistency and item analysis; and, (d) Preliminary data analyses. The open-ended questions were scored from 0 to 2 on the basis of their correctness and completeness by the first author and an independent judge. Cohen's Kappa values are reported below. A zero-score meant that a completely false answer was given. A score of one meant that a semi-correct or incomplete answer was given, and a score of two meant that a fully correct and complete answer was given. No responses were treated as non-responses and were excluded from the analysis. The content of the items referred to core concepts of each SSI. Sample items are 
given in Appendix D. For the prior knowledge instrument during the pilot test, an inter-rater reliability process was conducted by the first author and an independent judge using $30 \%$ of the tests. Reliability was estimated using Cohen's Kappa with all disagreements resolved by discussion. Table 3 displays examples of students' responses and the corresponding scores $(0,1$ and 2).

Table 3

Before the concept map task began, a short introduction to concept mapping was given to the students to ensure that all participants were familiar with this instrument. This decision was taken because, during the pilot study, some students did not know how to create a concept map. In particular, they were shown how concepts can be arranged graphically in a network in order to construct visual representations of their knowledge and understanding. They were taught to link all the concepts that they could (with arrows indicating the direction in which a link was to be read), and to label these links with statements that explained their interaction. Additionally, the participants were encouraged to follow five steps for the construction of their concept maps: (a) place the main concept at the top or the centre of the map, (b) organize the words (concepts) from most general to most specific, (c) use a linking word (verb, preposition, or short phrase) to connect and illustrate the relationship between the different concepts, (d) use crosslinks to make connections between concepts in different parts of the map, if needed, and (e) when finished, take a few moments to reflect on the map and modify it, if needed. Also, we emphasized the importance of developing maximum linkages as the best exposition of rich understanding.

The students were asked to use a list of ten concepts relevant to each SSI, which were provided to them, in order to create a network concept map, describing the appropriate relationships between the relevant concepts. We decided to use a list of ten basic concepts for the construction of each SSI-concept map because in this way all participants had available some relevant background knowledge that they could use if they wished. Participants differed in the 
number of concepts they used, from 0 to 10 . Using a scoring system already reported in the literature (Kyza, Constantinou, \& Spanoudis, 2011; Yin et al., 2005), we counted the number of appropriate concepts and the number and quality of appropriate relationships between concepts (propositions) for each student's concept map. Appendix E includes the levels that were used to score the propositions, examples of how the scoring system has been applied to score students' concept maps, and three illustrative examples.

For the open-ended questions and the concept maps, $30 \%$ of the data from each instrument and each of the three SSIs were coded by an independent judge. Inter-rater reliability for open-ended questions was estimated using Cohen's Kappa as follows:

For SSI-1 question $1: \mathrm{k}=.92$; for question $2: \mathrm{k}=.90$; for question: $3: \mathrm{k}=.89$, for question $4: \mathrm{k}=91$; for question $5: \mathrm{k}=.93$. For the concept mapping Cohens' kappa was calculated as $\mathrm{k}=$ 90. All disagreements were resolved through discussion between the two coders.

For SSI-2 question $1: \mathrm{k}=.90$; for question $2: \mathrm{k}=.90$; for question: $3: \mathrm{k}=.89$, for question $4: \mathrm{k}=.91$; for question $5: \mathrm{k}=.90$, and for the concept mapping $\mathrm{k}=.89$, with all disagreements resolved after discussion between the two coders.

For SSI-3 question $1: \mathrm{k}=.89$; for question $2: \mathrm{k}=.92$; for question: $3: \mathrm{k}=.90$, for question $4: \mathrm{k}=.91$; for question $5: \mathrm{k}=.88$, and for the concept mapping $\mathrm{k}=.88$, again with all disagreements resolved after discussion between the two coders. After establishing a satisfactory percentage of agreement between the two coders, $90 \%$, the first author coded the remaining tests.

\section{Argument construction.}

Students' individual argument skills were assessed using a written instrument based on published work (Kuhn, Goh, Iordanou, \& Shaenfield, 2008; Wu \& Tsai 2011). In particular, students were asked to take a position for each topic-dilemma and justify it by formulating supportive arguments, counterarguments and rebuttals. Students were prompted to construct different types of arguments, social, ethical, economic, scientific and ecological, expressing their 
opinion, by providing a particular space in the instrument for each type of argument. The instrument used for SSI 2 is presented in Appendix F. We asked for supportive arguments, counterarguments and rebuttals because, according to Nussbaum and colleagues (2008) and Naess (1966), arguments should be analyzed by examining the reasons in support of a conclusion (supportive arguments), and those supporting the opposite conclusion (counterarguments). Counterarguments can also show why a supportive argument is weak or flawed. Such arguments have also been referred to as refutations, undercutting defeaters, or counter-counterarguments. Although there is no consensus on how various authors use these terms, we adopted the approach of Kuhn (1991) who used the term rebuttal to refer to an argument refuting a counterargument (i.e., a counterargument to a counterargument).

Since we are interested in the construction of different types of arguments and not argumentation per se, the students had to list their different types of arguments instead of writing one coherent text weighing and synthesizing strategies (argument-counterargument integration, see Nussbaum et al., 2008). For example, for the topic of whether vaccines are safe and should be used against the NUEVO flu virus, students were asked to answer the following questions: 1. Are you for or against vaccination for the NUEVO flu virus? 2. If you want to convince a friend about your position, what arguments will you put forward to convince them? 3. If somebody holds an opposite position from yours on this issue, what arguments may he/she have? 4. According to the argument you mentioned in question 3, can you write down your opposite arguments to justify your position? (See Appendix F)

For each participant, we computed the total number and assessed the quality of valid supportive arguments, counterarguments and rebuttals constructed, as well as the diversity of the different types of arguments - social, ethical, economic, scientific and ecological - as presented in Appendix G. Additionally, in Appendix G further explanation of the nature of the different types of arguments is given. A supportive argument, counterargument and rebuttal was considered valid if it involved the presentation of a claim and the legitimacy of that claim was 
documented through justification based on evidence. The quality of supportive arguments, counterarguments and rebuttals was determined based on a scoring scheme adapted from Sadler and Fowler (2006). The coding scheme took into consideration the number and accuracy of the pieces of evidence that were provided to support a claim. Thus, arguments that involved many pieces of valid and reliable evidence were considered to be stronger than arguments with only one piece of evidence (Sadler \& Fowler, 2006). The quality of arguments produced was scored from 0 to 4 , as presented in Table 4 a.

For coding the diversity of argument types, we followed two steps: (1) We checked the nature of each argument provided under each prompt for argument type in the instrument (see Appendix G), giving 1 point for each simple argument type. In this step, it was possible for one argument to be coded as a type other than the argument type in which the participant chose to register it under. (2) If there were multiple arguments provided under one prompt (e.g. an economic argument with elements of ethical or social considerations, which were not provided again in the space for ethical or social arguments), we coded them separately. A particular argument claim could only be classified into one type (e.g. economic). Complex arguments (e.g. economic and ethical) were classified for each claim separately.

Tables $4 \mathrm{a}, 4 \mathrm{~b}$ and $4 \mathrm{c}$ show examples of students' arguments based on their quality, function (supportive arguments, counterarguments and rebuttals) and type, respectively.

Table $4 \mathrm{a}$

Table 4b

Table 4c

Inter-rater reliability was evaluated for the first author and an independent judge using a random sample of $30 \%$ of the tests for each SSI questionnaire. Reliability for quality was estimated at $92 \%$ (Cohens' $\mathrm{k}=.92)$ while reliability for number of arguments was estimated at 
$97 \%($ Cohens' $\mathrm{k}=.97)$ and for diversity of argument types at 92\% (Cohens' $\mathrm{k}=.92)$, with all disagreements resolved after discussion between the two coders. Following this, the first author coded the remaining tests.

To examine whether epistemic beliefs (epistemic dimensions), prior knowledge (concept map and open-ended questions) and the SSI context can predict the number, quality and diversity of different types of arguments produced, multiple hierarchical regression analyses were carried out with the epistemic beliefs (epistemic dimensions), prior knowledge (concept map and openended questions) and SSI context as predictors (see Appendix I for assumptions of regression analyses). The prior knowledge variables (concept map and open-ended questions) were entered in the first step, as the prior knowledge task was a kind of pre-task, while epistemic dimension variables were entered in the second step, and the dummy variables for SSI context in the third step.

\section{Pilot study.}

All instruments employed in this study were pilot tested, using a sample of undergraduate students, before refinement of the final versions. Participants in the pilot studies were education students at the same public University as the participants of the main study. None of the participants in any of the pilot studies took part in the main study.

DEBS instrument. For the DEBS instrument, participants were 295 undergraduate students. The initial version of the DEBS instrument, before pilot testing, consisted of five subscales (dimensions) and 40 items. Initially, we asked 20 undergraduate students to provide feedback on the readability and perceived relevance of the items of the questionnaire. Additionally, we asked five other undergraduate students to rewrite all items in their own words. Based on the feedback we received in the pilot testing, we deleted or rewrote a number of items. The revised version of the instrument, consisting of five subscales and a total of 35 items, was further submitted to a large-scale validation procedure in order to establish the validity and 
internal consistency of the instrument. The instrument was further revised based on the findings of the validation processes, resulting in the final version, which consists of five subscales and 30 items.

Argument construction instrument. Initially, we provided 55 undergraduate students with the topic-dilemmas that were used in the present study, asking them to take a position for each topic-dilemma and justify it by formulating supportive arguments, counterarguments and rebuttals providing as many different types of arguments as they see fit. The results of this pilot study showed that the students produced only 1-2 types of arguments. Based on this finding, we decided to offer additional support to students, examining if students can produce different types of arguments when they are explicitly prompted to do so by providing them different category type prompts. Therefore, in the revised instrument we explicitly added different categories of types of arguments (social, ethical, economic, scientific, and ecological) and asked them to provide as many relevant arguments as possible, according to their opinion.

Prior knowledge instrument. Initial versions of the instruments assessing participants' prior knowledge for each SSI-topic, each consisting of six open-ended questions and a concept map, were pilot tested using a sample of 55 undergraduate students. Additionally, we asked 20 undergraduate students to provide feedback on the readability and comprehension of the questions of the instruments, based on their prior knowledge. The mean scores for each of the six questions (average for the three SSIs) that were obtained in the pilot study of prior knowledge were the following $M_{Q 1}=1.38, M_{Q 2}=1.13, M_{Q 3}=1.27, M_{Q 4}=1.29, M_{Q 5}=1.35, M_{Q 6}=0.55$. The results of this pilot study showed that the students had unacceptably low scores in one question of each instrument $\left(M_{Q 6}=0.55\right)$. Based on the results of each open-ended question and the feedback from the 20 undergraduate students, we removed one item from each prior knowledge instrument, whose content was not adequately taught to the students. Furthermore, some items were rewritten in order to make the wording more precise. This procedure resulted in five openended questions in the final version of each instrument. 


\section{Main study.}

Each participant took part in 3 sessions. In the first session, lasting 20 minutes, the epistemic beliefs measure was administered. In the second session, which took place right after the first session and lasted 40 minutes, the prior knowledge instrument was administered. A 30minute break took place between the second and the third session. The order of tasks in the third session was as follows: (a) reading the SSI scenario on one of the three topics, (b) reading the SSI information related to the SSI scenario, and (c) constructing arguments. Students were given unlimited time to complete the tasks of the third session. This third session lasted from 40 to 60 minutes. To obtain an adequate sample size, given the small number of registered students per semester at the University of Cyprus, the data collection was completed over five academic semesters in a period of 2.5 years. The first author conducted the data collection, which took place at the University of Cyprus. One participant was excluded from the analysis because he did not complete all tasks.

\section{Results}

To answer our research questions Pearson correlations were calculated in order to investigate if the variables of the study were positively or negatively and significantly correlated among them. Then, to answer whether epistemic beliefs, prior knowledge on SSI and SSI-context predict the quantity, quality and diversity of different types of arguments (supportive arguments - social, ethical, economic, scientific, ecological arguments - as well as counterarguments, and rebuttals) produced by university students, hierarchical multiple regression analyses were carried out. The multiple regression approach enables us to examine a relationship between a dependent variable and multiple independent variables.

\section{Preliminary Results}

The means, standard deviations, minimum and maximum scores, and values of skewness and kurtosis of all variables of this study are reported in Table 5. 
Table 5

The measures of skewness and kurtosis indicated that all score distributions were approximately normal and, thus, appropriate for use in parametric statistical analyses. As seen in Table 5, participants' scores on the epistemic beliefs measure suggested relatively sophisticated beliefs about certainty, justification and development of knowledge, and less sophisticated beliefs about simplicity (structure of knowledge) and source of knowledge.

Table 6 displays the Pearson correlations between all variables for prior knowledge, epistemic beliefs and arguments construction of the current study. First, results of the Pearson correlation indicated that there was a relatively weak positive correlation (Cohen, 1988; 1992) between the concept map score and the open-ended questions score $(r=0.14, p<0.05)$, suggesting that the two measures of knowledge are not assessing exactly the same aspects. Openended questions focus on a single concept, while a concept map focuses on the relational links between relevant concepts (Novak, 1998). Second, the Pearson correlation values indicated that there was a weak positive correlation between the prior knowledge concept map score (but not the open-ended questions score $)$ and the simplicity dimension of knowledge, $(r=0.19, p<0.01)$, suggesting that more sophisticated epistemic beliefs (beliefs about the structure of knowledge) were correlated with high prior knowledge scores on the concept map.

Third, results of Pearson correlation showed that there was a statistically significant correlation between the quantity, the quality and the diversity of different types of arguments on SSIs. In particular, there is a strong positive correlation between Quality of arguments and Number of arguments $(r=0.63, p<0.01)$, a moderate positive correlation between Diversity of arguments and Number of arguments $(r=0.41, p<0.01)$ and a moderate positive correlation between Quality of arguments and Diversity of arguments $(r=0.38, p<0.01)$. Additionally, results showed a significant weak positive correlation between the prior knowledge scores and 
the arguments that were constructed. More specifically, as seen in Table 6, there was a weak positive correlation between the arguments constructed - quantity $(r=0.29, p<0.01)$, quality ( $r$ $=0.33, p<0.01)$, and diversity $(r=0.22, p<0.01)$ of different types of arguments - and the prior knowledge scores $(r=0.25, p<0.01)$, the prior knowledge-concept map scores $(r=0.22, p<$ $0.01)$ and the prior knowledge open-ended questions $(r=0.08, p<0.05)$.

Table 6

Regarding epistemic beliefs and construction of arguments, we found that there was a significant weak positive correlation between the simplicity dimension and the quantity $(r=0.23$, $p<0.01)$, quality $(r=0.24, p<0.01)$ and diversity of different types of arguments $(r=0.31, p<$ 0.01). A weak positive correlation was also observed between the source beliefs dimension and the number of arguments $(r=0.17, p<0.01)$.

\section{Prior Knowledge, Epistemic Beliefs and Context as predictors of Argument Skills}

To answer the first research question, namely to examine the relationship between university students' prior knowledge and epistemic beliefs and the number, quality and diversity of arguments they construct on a controversial socio-scientific topic, multiple regression analysis was conducted using prior knowledge (open-ended questions and concept map) and epistemic beliefs (epistemic dimensions according to the multidimensional perspective) as the predictor variables.

To answer the second research question, namely, to investigate the effects of the context of the three SSI-scenarios on the quantity, quality and diversity of different types of arguments produced, two dummy variables were created, which were related to the context of SSI-scenarios. The SSI 3: Usage of underground vs. overhead high voltage lines in residential areas was used as the reference category. The first dummy variable was SSI 1: Usage or not usage of vaccines 
against the NUEVO flu virus (vs SSI 3), while the second dummy variable was SSI 2: Consumption of bottled vs. tap water (vs SSI 3).

Table 7 displays the unstandardized regression coefficients $(B)$ and intercept, the standardized regression coefficients $(\beta), R^{2}$ and adjusted $R^{2}$ after entry of all independent variables (IVs).

Table 7

\section{Quantity of Arguments}

After step 3, with all IVs in the equation, the model was statistically significant, $R^{2}=.20$, $F(9,231)=6.50, p<0.001$. The adjusted $R^{2}$ value of 0.18 indicates that $18 \%$ of the variability in the quantity of arguments is predicted by prior knowledge, epistemic beliefs and SSI-context.

After step 1, with prior knowledge (concept map and open-ended questions) in the equation, $R^{2}=.13, F_{\text {inc }}(2,238)=17.21, p<0.001$. The adjusted $R^{2}$ value of 0.12 indicates that $12 \%$ of the variability in the quantity of arguments is predicted by prior knowledge. After step 2 , with the addition of epistemic beliefs (Certainty, Simplicity, Source, Justification and Development of Knowledge) to the prediction of quantity of arguments by prior knowledge, $R^{2}$ $=.17, F_{\text {inc }}(5,235)=2.48, p<0.01$. The adjusted $R^{2}$ value of 0.15 indicates that $15 \%$ of the variability in the quantity of arguments is predicted by prior knowledge and epistemic beliefs. Addition of epistemic beliefs to the equation of prior knowledge results in a significant increment in $R^{2}$ by 0.04 . After step 3, with SSI-context added to prediction of quantity of arguments by prior knowledge and epistemic beliefs, $R^{2}=.20, F_{\text {inc }}(2,238)=4.56, p<0.01$. The adjusted $R^{2}$ value of 0.18 indicates that $18 \%$ of the variability in the quantity of arguments is predicted by prior knowledge and epistemic beliefs. Addition of SSI-context to the equation improved $R^{2}$ by 0.03. The pattern of results suggests that $12 \%$ of the variability in the quantity of arguments constructed is predicted by prior knowledge. Epistemic beliefs contribute modestly to that prediction; SSI-context adds further to that prediction. 


\section{Quality of Arguments}

After step 3, with all IVs in the equation $R^{2}=0.19, F(9,231)=5.96, p<0.001$. The adjusted $R^{2}$ value of 0.15 indicates that $15 \%$ of the variability in the quality of arguments is predicted by prior knowledge, epistemic beliefs and SSI-context.

After step 1, with prior knowledge (concept map and open-ended questions) in the equation, $R^{2}=.14 F_{\text {inc }}(2,238)=18.98, p<0.001$. The adjusted $R^{2}$ value of 0.13 indicates that $13 \%$ of the variability in the quality of arguments is predicted by prior knowledge. After step 2, with the addition of epistemic beliefs (Certainty, Simplicity, Source, Justification and Development of Knowledge) to the prediction of quality of arguments by prior knowledge, $R^{2}=$ $.18, F_{\text {inc }}(5,235)=2.25, p=0.04$. The adjusted $R^{2}$ value of 0.16 indicates that $16 \%$ of the variability in the quality of arguments is predicted by prior knowledge and epistemic beliefs. Addition of epistemic beliefs to the equation of prior knowledge results in a significant increment in $R^{2}$ by 0.04 . After step 3 , with SSI-context added to prediction of quality of arguments by prior knowledge and epistemic beliefs, $R^{2}=.19, F_{\text {inc }}(2,238)=0.83, p=0.44$. The adjusted $R^{2}$ value of 0.15 indicates that $15 \%$ of the variability in the quality of arguments is predicted by prior knowledge, epistemic beliefs and SSI-context. The pattern of results suggests that $13 \%$ of the variability in the quality of arguments constructed is predicted by prior knowledge. Epistemic beliefs contribute modestly to that prediction by 0.006 . Addition of SSI-context to the equation did not significantly improve $R^{2}$.

\section{Diversity of Arguments}

After step 3, with all IVs in the equation $R^{2}=.19, F(9,231)=5.96, p<0.001$. The adjusted $R^{2}$ value of 0.16 indicates that $16 \%$ of the variability in the diversity of arguments is predicted by prior knowledge, epistemic beliefs and SSI-context. 
After step 1, with prior knowledge (concept map and open-ended questions) in the equation, $R^{2}=.05 F_{\text {inc }}(2,238)=6.07, p<0.01$. The adjusted $R^{2}$ value of 0.04 indicates that $4 \%$ of the variability in the diversity of arguments is predicted by prior knowledge. After step 2, with the addition of epistemic beliefs (Certainty, Simplicity, Source, Justification and Development of Knowledge) to the prediction of diversity of arguments by prior knowledge, $R^{2}=.17$, $F_{\text {inc }}(5,235)=6.87, p<0.001$. The adjusted $R^{2}$ value of 0.15 indicates that $15 \%$ of the variability in the diversity of arguments is predicted by prior knowledge and epistemic beliefs. Addition of epistemic beliefs to the equation of prior knowledge results in a significant increment in $R^{2}$ by 0.12. After step 3, with SSI-context added to prediction of diversity of arguments by prior knowledge and epistemic beliefs, $R^{2}=.19, F_{\text {inc }}(2,238)=2.51, p=0.08$. The adjusted $R^{2}$ value of 0.16 indicates that $16 \%$ of the variability in the diversity of arguments is predicted by prior knowledge and epistemic beliefs. Addition of SSI-context to the equation did not significantly improve $R^{2}$. The pattern of results suggests that $5 \%$ of the variability in the diversity of arguments constructed is predicted by prior knowledge. Epistemic beliefs contribute to that prediction; Addition of SSI-context to the equation did not significantly improve $R^{2}$.

Table 8 displays the Pearson correlations between epistemic beliefs variables and different types of arguments. As seen in Table 8, there was a weak positive correlation between the simplicity dimension and the number of ethical $(r=0.24, p<0.01)$, economic, $(r=0.18, p<$ $0.01)$ and scientific $(r=0.26, p<0.01)$ arguments.

Table 8

\section{Discussion and Conclusions}

The aim of the present study was to investigate possible relationships between epistemic beliefs, prior knowledge, and construction of different types of arguments on socio-scientific 
issues (SSIs). We examined whether prior knowledge (concept map and open-ended questions), epistemic beliefs (epistemic dimensions) and SSI-context predict the quantity, quality and diversity of different types of arguments (supportive arguments - social, ethical, economic, scientific, ecological - counterarguments and rebuttals) constructed by university students on one of three complex controversial, socio-scientific topics. We start with discussing our findings from the correlations among the variables that we examined and then we proceed with discussing the major findings regarding how prior knowledge, epistemic beliefs and SSI-context predict students' argument skills.

The results of the present study demonstrate an association between prior topic knowledge and the number as well as the quality of arguments produced on a complex SSI. This finding is in line with previous research showing that topic knowledge is essential for the construction of more than one arguments on a socio-scientific topic (Means \& Voss, 1996; Mason \& Scirica, 2006; Sadler \& Fowler, 2006) and for the construction of high quality arguments (Mason \& Scirica, 2006; Osborne et al., 2016; Sadler \& Fowler, 2006; Wu \& Tsai, 2011). Our findings extend the current literature by showing that robust prior topic knowledge is essential not only for the quantity and quality of arguments but also for the diversity of different types of arguments that students construct, in their effort to take under consideration multiple sides and perspectives of a socio-scientific topic. This finding is revealing of the important role of prior topic knowledge on scientific creativity, at least in relation to the facility to generate alternative arguments and interpretations (Sawyer, 2012).

Regarding the relationship between prior knowledge and epistemic beliefs, our results demonstrate an association between epistemic beliefs, particularly beliefs about the structure of knowledge, and depth of prior knowledge, when the latter was assessed through concept mapping (Hiebert \& Carpenter, 1992; Hiebert \& Lefevre, 1986), but not with prior knowledge of isolated scientific concepts, which was assessed by open-ended questions (Hiebert \& Carpenter, 1992; Hiebert \& Lefevre, 1986) related to a SSI. This finding is in line with previous research 
suggesting that epistemic beliefs may limit or promote conceptual change and topic conceptual understanding (Amin, Smith \& Wiser, 2014; Stathopoulou \& Vosniadou, 2007a; 2007b; Trevors, Kendeou et al., 2017; Trevors, Muis et al., 2017). For example, students who think science involves only description of facts may be more likely to focus on isolated phenomena. On the other hand, those who think science is more complex and involves interrelated concepts and justifications, are more likely to rely on multiple sources and tend to look for organizing principles and patterns of relationships, achieving therefore deeper conceptual understanding. Another interpretation for this finding is that less sophisticated epistemic beliefs about the structure of knowledge (i.e. beliefs in simple knowledge with discrete pieces of factual information) may activate one's goal to memorize information, which elicits superficial processing strategies such as rote rehearsal (Ioannou \& Iordanou, 2019). In contrast, epistemic beliefs in complex knowledge (sophisticated simplicity beliefs) may activate one's goal to understand the available information and develop coherent conceptualizations, eliciting deeper processing strategies (e.g. making connections, integrating ideas, creating concept maps) or considering a SSI from multiple perspectives and alternative viewpoints. From this perspective, the relationship between epistemic beliefs and conceptual understanding is likely to be reciprocal to some degree (Pintrich, 2002). Since personally held beliefs about scientific knowledge and knowing are themselves subject to change, it is rather reasonable to suggest that deeper understanding of a knowledge domain may provide feedback that influences epistemic beliefs (Chinn \& Duncan, 2018).

Turning now to the major findings of the present study, our results indicate that prior knowledge (as assessed by a concept map and open-ended questions) and the epistemic dimension of simplicity of knowledge (beliefs about the structure of knowledge) have significant predictive power for the quantity, the quality and the diversity of different types of the arguments (supportive arguments - social, ethical, economic, scientific, ecological - counterarguments and rebuttals) that university students construct on a complex, controversial, socio-scientific topic. 
Our results further show that the SSI-context has a significant predictive power for the quantity of arguments that student construct, but not for the quality or the diversity of the arguments.

The finding that prior knowledge and epistemic beliefs predict the quantity and quality of arguments is consistent with previous findings reported in the literature, as discussed above (Iordanou, Kendeou, \& Beker, 2016; Iordanou \& Constantinou, 2015; Mason \& Scirica, 2006; Sadler \& Fowler, 2006; Wu \& Tsai, 2011). Yet, the finding that epistemic beliefs and prior knowledge predict the diversity of different types of arguments that students construct constitutes a novel contribution of the present study. This finding provides insight into our understanding for the development of a theoretical framework for dealing with controversial SSIs, suggesting that students need deep topic conceptual understanding and an epistemic understanding theorizing knowledge as a complex system of organized theoretical principles and ideas (sophisticated simplicity epistemic beliefs) for dealing effectively with complex controversial SSIs. Sufficiently developed content knowledge and epistemic understanding enabled students in the present study to appreciate the complexity and multidimensionality of SSIs, as was reflected in students' ability to produce arguments from multiple perspectives. We argue that robust prior knowledge is necessary for the construction of different types of arguments because students must have a well-developed conceptual schema in order to incorporate content knowledge in their different types of arguments (Sadler \& Fowler, 2006; Sadler \& Zeidler, 2005).

The finding that sophisticated simplicity epistemic beliefs predicted the diversity of arguments produced on SSIs, above and beyond prior knowledge is of particular importance, highlighting the role of epistemic beliefs in particular, for constructing different types of arguments on a SSI. A possible explanation for this finding that epistemic simplicity beliefs predicted construction of different types of arguments (diversity of arguments), mainly arguments about the ethical, economic and scientific aspects of a SSI, is the following: Students who view knowledge as a collection of simple and discrete pieces of factual information (naïve simplicity beliefs), rather than as a complex system of organized theoretical concepts 
(sophisticated simplicity beliefs), may tend not to: 1) develop an understanding of the complex controversial nature of a socio-scientific topic; 2) consider alternative views, and/or 3) recognize that some aspects of an issue have more and different implications as well as ethical dimensions. Additionally, if students believe that knowledge is simple, they probably do not appreciate the need to include different evidence and diverse perspectives in their arguments, or the need to seek further evidence or to integrate conflicting information from multiple sources. The finding that only the simplicity dimension of the multidimensional approach was associated with argument skills could be explained taking into consideration that the multidimensional model of personal epistemic beliefs is a system of rather orthogonal, uncoordinated dimensions, that are more or less independent, not necessarily developing in synchrony with each other (Iordanou, 2016a; Muis et al., 2015). Muis et al. (2015) also argued that it is often the case that only one or two dimensions of the multidimensional model are particularly salient in a learning situation. In the present study, students were presented with a complex SSI for which connections among different pieces of information, perspectives and evidence were necessary, which probably made the simplicity dimension - about the structure of knowledge - more salient than the other epistemic dimensions.

In summary, the present study extends the current literature examining relationships between epistemic beliefs, prior knowledge and the construction of different types of arguments on complex controversial socio-scientific issues (SSIs). The findings of the present study show that students with relatively sophisticated simplicity beliefs and relatively robust prior topic knowledge construct not only more arguments, counterarguments and rebuttals, of higher quality, but also different types of arguments (diversity of arguments), than students with nonsophisticated simplicity beliefs and not robust prior topic knowledge. The former students constructed different types of arguments, mainly ethical, economic and scientific arguments, taking into consideration the complexity and multidimensionality of SSIs and avoiding oversimplification of the issues. 
Some limitations of the current study that may give impetus to further work in this area are important to mention. The first limitation concerns the diversity of the sample. Although the issues addressed in the current study are of international applicability, we cannot generalize our results based on a relatively small sample, consisting of $93 \%$ female participants. A second limitation concerns the time span of the data collection of the study. The data collection was completed in a period of 2.5 years, due to the small number of students who enter the education program at the particular university that the data were collected. The third limitation concerns the type of the instrument that was employed to assess epistemic beliefs. We used only a single instrument, a questionnaire, which does not probe elaborated participants' responses to items as in-depth interviews would do. Future studies could usefully take a closer look at the interplay between epistemic beliefs and argument construction using a multiplicity of methods, such as interviews and think-aloud protocols (Iordanou, Muis, \& Kendeou, 2019), but also a sample, at a particular time point, that would be balanced in terms of gender representation and age. A fourth limitation of this study is that only the refutation strategy was taken into account for the construction of arguments. Although the refutation strategy includes, to some extent, weighing and synthesizing strategies, other strategies, such as the integration strategy of the different confronting positions in an argument (Nussbaum \& Schraw, 2007), could also have been directly examined. Also, given that many Pearson coefficients in the present study were rather low (ranging from 0.17 to 0.36 ) regarding the relationships between epistemic beliefs, prior knowledge and argument skills, and also the $\mathrm{R}$ squared in the stepwise regression analyses for explaining different types of arguments was less than $25 \%$, further research is required to replicate these findings.

Nevertheless, our study has important educational implications, showing that relatively sophisticated simplicity epistemic beliefs and robust conceptual understanding are related with an individuals' argument skills, especially their ability to construct different types of arguments on SSIs, elucidating the complex and multidimensional nature of SSIs. Additionally, the finding 
of the present study that undergraduate education students' epistemic beliefs and conceptual understanding are not optimally developed for dealing with SSIs, point to the need to invest on efforts fostering individuals' epistemic beliefs, especially their simplicity beliefs, and conceptual understanding. We need to find ways for supporting what Barzilia and Chinn (2017) refer to as epistemic education for promoting apt epistemic performance.

Engagement in dialogic argumentation might be a promising way for supporting both objectives, namely acquiring content knowledge (Asterhan \& Schwarz, 2016; Iordanou \& Kuhn, 2019; Iordanou, Kuhn, Matos, Shi, \& Hemberger, 2019) and developing evaluativist epistemic beliefs (Iordanou, 2016a; 2016b). Promoting teachers' epistemic beliefs should be one of the major objectives of efforts aiming to promote young people's argument skills. Iordanou and Constantinou (2014) have shown that engaging pre-service teachers in a program based on argumentative and reflective activities appears to be a promising pathway for supporting preservice teachers to develop their epistemic beliefs and their conceptual understanding. Engagement in dialogic argumentation on SSIs in particular, might further facilitate fostering individuals' epistemic beliefs, since SSIs are complex open-ended problems, involving multiple aspects, approaches, perspectives, ethical considerations and conflicting information, all of societal relevance. In addition, prompting students to think of the different aspects involved in SSIs (social, ethical, economic, scientific, ecological, etc.) may support the development of students' awareness of the complex nature of the SSIs, facilitating further the development of students' epistemic simplicity beliefs. More research is required to examine this possibility. Future efforts also need to focus on finding the means for supporting the development of preservice teachers' epistemic beliefs, particularly their epistemic simplicity beliefs, their understanding about the complexity and multidimensionality of SSIs and conceptual understanding. In doing so, we would empower pre-service teachers in their role later as teachers to foster the development of these forms of understandings among their future students, preparing them to function as responsible citizens in democratic societies, which require citizens to 
consider and evaluate different aspects, perspectives and viewpoints on complex issues in order to meaningfully engage in decision-making processes about themselves and their society.

\section{References}

Amin, T. G., Smith, C. L., \& Wiser, M. (2014). Student conception and conceptual change: Three overlapping phases of research. In N. G. Lederman \& S. K. Abell (Eds.), Handbook of research in science education ( $2^{\text {nd }}$ ed., pp. 57-81). New York, NY: Routledge.

Asterhan, C., \& Schwarz, B. (2016). Argumentation for learning: Well-trodden paths and unexplored territories. Educational Psychologist, 51, 164-187.

Barzilai, S., \& Eshet-Alkalai, Y. (2015). The role of epistemic perspectives in comprehension of multiple author viewpoints. Learning and Instruction, 36, 86-103.

Barzilai, S., \& Chinn, C. A. (2017). On the goals of epistemic education: Promoting apt epistemic performance. Journal of the Learning Sciences, 4, 1-37.

Baytelman, A., \& Constantinou, C. P. (2016). Development and validation of an instrument to measure epistemological beliefs in science. In J. Lavonen, K. Juuti, J. Lampiselkä, A. Uitto and K. Hahl (Eds.), Proceedings of the ESERA 2015 Conference. Science education research: Engaging learners for a sustainable future, Part 11 (co-ed. Jens Dolin and Per Kind), (pp. 1047-1058). Helsinki, Finland: University of Helsinki.

Baytelman, A., Iordanou, K, \& Constantinou, C. P. (2016). The effects of epistemological beliefs and prior knowledge on the construction of arguments. In J. Lavonen, K. Juuti, J. Lampiselkä, A. Uitto and K. Hahl (Eds.), Proceedings of the ESERA 2015 
Conference. Science education research: Engaging learners for a sustainable future,

Part 7 (co-ed. M. Andrée and M. Pilar Jimenez-Aleixandre), (pp. 1047-1058). Helsinki, Finland: University of Helsinki.

Bell, P., \& Linn, M.C. (2000). Scientific arguments as learning artifacts: Designing for learning from the web with KIE. International Journal of Science Education, 22(8), 797-817.

Berland, L., \& Crucet, K. (2016). Epistemological trade-offs: Accounting for context when evaluating epistemological sophistication of student engagement in scientific practices. Science Education, 100(1), 5-29.

Berland, L. K., Schwarz, C.V., Krist, C.,Kenyon, L., Lo, A. S.,\&Reiser,B. J. (2016). Epistemologies in practice: Making scientific practices meaningful for students. Journal of Research in Science Teaching, 53(7), 1082-1112.

Brown, T. A. (2006). Confirmatory factor analysis for applied research. New York, NY, US: The Guilford Press.

Carey, S. (1985). Are children fundamentally different kinds of thinkers and learners than adults? In S. Chipman, J. Segal \& R. Glaser (Eds.), Thinking and learning skills (Vol.2, pp. 485-514). Hillsdale: Lawrence Erlbaum and Associates.

Chinn, C. A., \& Duncan, R. G. (2018). What is the value of general knowledge of scientific reasoning? In F. Fischer, C. A. Chinn, K. Engelmann, \& J. Osborne (Eds.), Scientific Reasoning and Argumentation (pp. 87-111). Routledge.

Cohen, J. (1988). Statistical power analysis for the behavioral sciences (2nd ed.). Hillsdale, NJ: Erlbaum.

Cohen, J. (1992). A power primer. Psychological Bulletin, 112(1), 155-159.

Conley, M., Pintrich, P., Vekiri, I., \& Harrison, D. (2004). Changes in epistemological beliefs 
in elementary science students. Contemporary Educational Psychology, 29(2), 186204.

Crooms, J., Sampson, V., Enderle, P. (2018). How concept familiarity and experience with scientific argumentation are related to the way groups participate in an episode of argumentation. Journal of Research in Science Teaching, 55(9), 1264-1286.

Dawson, V., \& Venville, G., (2013). Introducing High School Biology Students to Argumentation About Socioscientific Issues. Canadian Journal of Science, Mathematics and Technology Education, 13(4), 356-372.

Duncan, R. G., Chinn, C. A., \& Barzilai, S. (2018). Grasp of evidence: Problematizing and expanding the next generation science standards' conceptualization of evidence. Journal of Research in Science Teaching, 55(7), 907-937.

Duschl, R. A. (2008). Science education in 3 part harmony: Balancing conceptual, epistemic and social goals. Review of Research in Education, 32(2), 268-291

Elby, A., \& Hammer, D. (2001). On the substance of a sophisticated epistemology. Science Education, 85(5), 554-567.

Erduran, S., \& Jimenez-Aleixandre, M. P. (Eds.). (2007). Argumentation in science education: Perspectives from classroom-based research. Dordrecht, The Netherlands: Springer.

Greene, J. A., Sandoval, W. A., \& Bråten, I. (2016). Reflections and future directions. In J. A. Greene, W. A. Sandoval, \& I. Bråten (Eds.). Handbook of epistemic cognition. New York, NY: Routledge.

Griffin, P. (2005). Developing a measure of wealth for primary student families in a developing country: Comparison of two methods of psychometric calibration. Studies in Educational Evaluation, 31(2), 192-206. 
Hay, D. B. (2007). Using concept mapping to measure deep, surface and non-learning outcomes. Studies in Higher Education 32(1), 39-57.

Henderson, J. B., McNeill, K. L., González-Howard, M., Close, K., \& Evans, M. (2018). Key challenges and future directions for educational research on scientific argumentation. Journal of Research in Science Teaching, 55(1), 5-18.

Herman, B. C., Zeidler, D. L., \& Newton, M. (2018). Students' emotive reasoning through place-based environmental socioscientific issues. Research in Science Education, https://doi.org/10.1007/s11165-018-9764-1.

Hiebert, J., \& Lefevre, P. (1986). Conceptual and procedural knowledge in mathematics: An introductory analysis. In J. Hiebert (Ed.), Conceptual and procedural knowledge: The case of mathematics (pp. 1-28). Hillsdale, NJ: Erlbaum.

Hofer, B. K., Pintrich, P. R. (1997). The development of epistemological theories: beliefs about knowledge and knowing their relation to learning. Review of Educational Research, 67(2), 88-140.

Hu, L. T., \& Bentler, P. M. (1999). Cutoff criteria for fit indexes in covariance structure analysis: Conventional criteria versus new alternatives. Structural Equation Modeling, 6, 1-55.

Ioannou, K., \& Iordanou, K. (2019). Elementary school students' epistemic perspective and learning strategies in history. Learning: Research and Practice.

Iordanou, K. (2010). Developing argument skills across scientific and social domains. Journal of Cognition and Development. 11(3), 293-327.

Iordanou, K. (2016a). From theory of mind to epistemic cognition. A Lifespan perspective. Frontline Learning Research, 4(5), 106 - 119. 
Iordanou, K. (2016b). Developing epistemological understanding through argumentation in scientific and social domains. Zeitschrift für Pädagogische Psychologie. 30(2-3), 109-119.

Iordanou, K. \& Constantinou. C. P. (2014). Developing pre-service teachers' evidencebased argumentation skills on socio-scientific issues. Learning \& Instruction. 34, 4257.

Iordanou, K. \& Constantinou. C. P. (2015). Supporting use of evidence in argumentation through practice in argumentation and reflection in the context of SOCRATES learning environment. Science Education, 99, 282-311.

Iordanou, K., \& Kuhn, D. (2020). Contemplating the Opposition: Does a Personal Touch Matter? Discourse Processes, 57(4), 343-359.

Iordanou, K., Kuhn, D., Matos, F., Shi, Y., \& Hemberger, L. (2019). Learning by arguing. Learning and Instruction, 63, 101-207.

Iordanou, K., Muis, K. R., \& Kendeou, P. (2019). Epistemic perspective and online epistemic processing of evidence: Developmental and domain differences. The Journal of Experimental Education, 87(4), 531-551.

Iordanou, K., Kendeou., P., \& Beker, K. (2016). Argumentative reasoning. In W. Sandoval, J. Greene, \& I., Bråten. (Eds.), Handbook of epistemic cognition (pp. 51-65). New York, NY: Routledge.

Jiménez-Aleixandre, M. P. (2014). Determinism and underdetermination in genetics: Implications for students' engagement in argumentation and epistemic practices. Science \& Education, 23(2), 465-484.

Kitchener, R. (2002). Folk epistemology: An introduction. New Ideas in Psychology, 20, 89105. 
Kleickmann, T., Richter, D., Kunter, M., Eisner, J., Besser, M., Krauss, S., \& Baumert, J. (2012). Teachers' content knowledge and pedagogical content knowledge: The role of structural differences in teacher education. Journal of Teacher Education, 20, 117.

Koslowski, B. (1996). Theory and evidence: The development of scientific reasoning. Cambridge, MA: MIT Press

Kuhn, D. (1991). The skills of argument. Cambridge, UK: Cambridge University Press.

Kuhn, D. (2001). How do people know? Psychological Science, 12, 1-8.

Kuhn, D., Cheney, R., \& Weinstock, M. (2000). The development of epistemological understanding. Cognitive Development, 15(3), 309-328.

Kuhn, D., Goh, W., Iordanou, K., \& Shaenfield, D. (2008). Arguing on the computer: A microgenetic study of developing argument skills in a computer-supported environment. Child Development, 79(1), 233-234.

Kuhn, D., Iordanou, K., Pease, M., \& Wirkala, C. (2008). Beyond control of variables: What needs to develop to achieve skilled scientific thinking? Cognitive Development, $23,435-451$.

Kyza, E., Constantinou, C. P. \& Spanoudis, G. (2011). Sixth graders' co-construction of explanations of a disturbance in an ecosystem: exploring relationships between grouping, reflective scaffolding and evidence-based explanations. International Journal of Science Education, 33(18), 2489-2525.

Lee, H., Lee, H. \& Zeidler, D. L. (2019). Examining tensions in the socioscientific classroom: Students' border crossings into a new culture of science. Journal of Research in Science Teaching. DOI: 10.1002/tea.21600 
Limón, M. (2006). The domain generality-specificity of epistemological beliefs: A theoretical problem, a methodological problem or both? International Journal of Educational Research, 45(1-2), 7-27.

Lindahl, M, Folkesson, A. \& Zeidler, D. (2019). Students' recognition of educational demands in the context of a socioscientific issues curriculum. Journal of Research in Science Teaching, 56(9) 1155-1182.

Mason, L., (2016). Psychological perspectives on measuring epistemic cognition. In W. Sandoval, J. Greene, \& I., Bråten. (Eds). Handbook of epistemic cognition, (pp. 375392). New York, NY: Routledge.

Mazur, E., (1997). Peer Instruction: A User's Manual, Prentice-Hall, Upper Saddle River, NJ.

McNeill, K. L., González-Howard, M., Katsh-Singer, R., \& Loper, S. (2017). Moving beyond pseudoargumentation: Teachers' enactments of an educative science curriculum focused on argumentation. Science Education, 101(3), 426-457.

Means, M. \& Voss, J. (1996). Who reasons well? Two studies of informal reasoning among children of different grade, ability, and knowledge levels. Cognition and Instruction, 14(2), 139-178.

Muis, K., Pekrun, R., Sinatra, G., Azevedo, R., Trevors, G., Meier, E., Heddy, B. (2015). The curious case of climate change: Testing a theoretical model of epistemic beliefs, epistemic emotions, and complex learning. Learning and Instruction, 39(2), 168-183.

Naess, A. (1966). Communication and argument: Elements of applied semantics. Oslo, Stockholm: Universitetsforlaget, Sv. Bokförlag.

Novak, J. D. (1998). Learning, creating, and using knowledge: Concept maps as facilitative tools for schools and corporations. Mahwah, NJ: Lawrence Erlbaum \& Assoc. 
Novak, J. D. (2006). The development of the concept mapping tool and the evolution of a new model for education: Implications for mathematics education. Focus on Learning Problems in Mathematics, 28(3\&4), 1-32.

Novak, J. D. (2010). Learning, creating, and using knowledge: Concept maps as facilitative tools in schools and corporations (2nd ed.). New York, NY: Routledge.

Novak, J. D., \& Cañas, A. J. (2008). The theory underlying concept maps and how to construct and use them (Technical Report IHMC CmapTools 2006-01 Rev 2008-01). Pensacola, FL: Florida Institute for Human and Machine Cognition.

Nussbaum, E. M., \& Schraw, G. (2007). Promoting argument-counterargument integration in students' writing. The Journal of Experimental Education, 76(1), 59-92.

Nussbaum, E. M., Sinatra, G. M., \& Poliquin, A. (2008). The role of epistemic beliefs and scientific argumentation in science learning. International Journal of Science Education, 30(15), 1977-1999.

Osborne, J. F., Henderson, J. B., MacPherson, A., Szu, E., Wild, A., \& Yao, S. Y. (2016). The development and validation of a learning progression for argumentation in science. Journal of Research in Science Teaching, 53(6), 821-846.

Perry, W. (1970). Forms of intellectual and ethical development in the college years: A scheme. New York: Holt, Rinehart \& Winston.

Pintrich, P. R. (2002). Future challenges and direction for theory and research on personal epistemology. In B. K. Hofer \& P. R. Pintrich (Eds.), Personal epistemology: The psychology of beliefs about knowledge and knowing (pp. 389-414). Mahwah, NJ: Lawrence Erlbaum Associates, Inc.

Ryu, S., \& Sandoval, W. A. (2012). Improvements to elementary children's epistemic understanding from sustained argumentation. Science Education, 96(3), 488-526. 
Sadler, T. D. (2009). Situated Learning in science education: Socio-scientific issues as contexts for practice. Studies in Science Education, 45(1), 1-42.

Sadler, T., \& Fowler, S. (2006). A threshold model of content knowledge transfer for socioscientific argumentation. Science Education, 90(6), 986-1004.

Sadler, T., \& Zeidler, D. (2005). The significance of content knowledge for informal reasoning regarding socio scientific issues: Applying genetics knowledge to genetic engineering issues. Science Education, 89(1), 71-93.

Sawyer, R. K. (2012). Explaining creativity: The science of human innovation. Oxford: Oxford University Press.

Schauble, L. (1996). The development of scientific reasoning in knowledge-rich contexts. Developmental Psychology, 32(1), 102-119.

Schauble, L. (2018). In the eye of the beholder: Domain-General and domain-specific reasoning in science. In Scientific Reasoning and Argumentation (pp. 21-43). Routledge.

Schommer, M. (1990). Effects of beliefs about the nature of knowledge on comprehension. Journal of Educational Psychology, 82(3), 498-504.

Schommer, M., Crouse, A., \& Rhodes, N. (1992). Epistemological beliefs and mathematical text comprehension: Believing it is simple does not make it so. Journal of Educational Psychology, 84, 435-443.

Schommer-Aikins, M. (2004). Explaining the epistemological belief system: Introducing the embedded systemic model and coordinated research approach. Educational Psychologist, 39(1), 19-29.

Shulman, L. (1986). Those who understand: Knowledge growth in teaching. Educational Researcher, 15, 4-14. 
Songer, N.B., \& Linn, M.C. (1992). How do students' views of science influence knowledge integration? In M. K. Pearsall (Ed.), Scope, sequence and coordination of secondary school science, Volume II: Relevant research (pp. 197-219). Washington, DC: The National Science Teachers Association.

Stathopoulou, C., \& Vosniadou, S. (2007a). Exploring the relationship between physicsrelated epistemological beliefs and physics understanding. Contemporary Educational Psychology. 32(3), 255-281.

Stathopoulou, C., \& Vosniadou, S. (2007b). Conceptual change in physics and physicsrelated epistemological beliefs: A relationship under Scrutiny. In Vosniadou, S.; Baltas, A., \& Vamvakoussi, X. (Eds.), Handbook of relationship under Scrutiny. Reframing the Conceptual Change Approach in Learning and Instruction. ISBN: 0-08045355-4.

Toulmin, S. (1972). Human understanding: The collective use and evolution of concepts.

Princeton: Princeton University Press.

Trevors, G. J., Kendeou, P., Bråten, I., \& Braasch, J. L. (2017). Adolescents’ epistemic profiles in the service of knowledge revision. Contemporary Educational Psychology, 49, $107-120$.

Trevors, G. J., Muis, K. R., Pekrun, R., Sinatra, G. M., Muijselaar, M. L. (2017). Exploring the relations between epistemic beliefs, emotions, and learning from texts. Contemporary Educational Psychology, 48, 116-132.

Udell, W. (2007). Enhancing adolescent girls' argument skills in reasoning about personal and non-personal decisions. Cognitive Development, 22(3), 341-352. 
Von Aufschnaiter, C., Erduran, S., Osborne, J., \& Simon, S. (2008). Arguing to learn and learning to argue: Case studies of how students' argumentation relates to their scientific knowledge. Journal of Research in Science Teaching, 45(1), 101-131.

Voss, J., Blais, J., Means, M., Greene, T., \& Ahwesh, E. (1986). Informal reasoning and subject matter knowledge in the solving of economics problems by naive and novice individuals. Cognition \& Instruction, 3(3), 269-302.

Watkins, D. (1989). The role of confirmatory factor analysis in cross-cultural research. International Journal of Psychology, 24(6), 685-701.

Williams, C. G. (1998). Using concept maps to assess conceptual knowledge of function. Journal for Research in Mathematics Education 29(4), 414-421.

Wu, Y., \& Tsai, C. (2011). High school students' informal reasoning regarding a socioscientific issue, with relation to scientific epistemological beliefs and cognitive structures. International Journal of Science Education, 33(3), 371-400.

Xiao, S., \& Sandoval, W. A. (2016). Resolving Disagreements in evaluating epistemic and disciplinary claims in middle school science. Singapore: International Society of the Learning Sciences.

Yacoubian, H. A. (2018). Scientific literacy for democratic decision-making. International Journal of Science Education, 40(3), 308-327.

Yin, Y., J. Vanides, M. A. Ruiz-Primo, C. C., Ayala, \& R. J. Shavelson. (2005). A comparison of two construct-a-concept-map science assessments: Created linking phrases and selected linking phrases. Journal of Research in Science Teaching 42 (2): 166-184.

Zavala, J., \& Kuhn, D. (2017). Solitary discourse is a productive activity. Psychological science, 28(5), 578-586. 
Zeidler, D. L. (2014). Socioscientific issues as a curriculum emphasis: theory, research and practice. In N. G. Lederman \& S. K. Abell (Eds.), Handbook of Research on Science Education, Volume II (pp. 697-726). New York, NY: Routledge.

Zeidler, D. L., Herman, B., Ruzek, M., Linder, A. \& Lin, S.S. (2013). Cross-cultural epistemological orientations to socioscientific issues. Journal of Research in Science Teaching, 50(3), 251-283.

Zeidler, D. L., Herman, B. C., \& Sadler, T. D. (2019). New directions in socioscientific issues research. Disciplinary and Interdisciplinary Science Education Research, 1(11), 1-9. https://doi.org/10.1186/s43031-019-0008-7

Zohar, A., \& Nemet, F. (2002). 'Fostering students' knowledge and argumentation skills through dilemmas in human genetics'. Journal of Research in Science Teaching, 39(1), 35-62. 